EXTENDED REPORT

\title{
A multidisciplinary job retention vocational rehabilitation programme for patients with chronic rheumatic diseases: patients' and occupational physicians' satisfaction
}

\author{
P D M de Buck, J Breedveld, F J van der Giesen, T P M Vliet Vlieland
}

Ann Rheum Dis 2004;63:562-568. doi: 10.1136/ard.2003.007260

See end of article for authors' affiliations

Correspondence to:

Dr P D M de Buck, Leiden

University Medical Centre, Department of

Rheumatology, C4-R, PO

Box 9600,2300 RC

Leiden, Netherlands;

pdmdebuck@lumc.nl

Accepted 25 June 2003

\begin{abstract}
Objective: To investigate patients' and occupational physicians' satisfaction with the quality of a vocational rehabilitation programme for maintaining work ability in chronic rheumatic diseases.

Methods: The vocational rehabilitation programme was developed for patients with rheumatic diseases and consisted of systematic assessment of the problems at work and the development of individual solutions. The programme was run by a multidisciplinary team comprising a rheumatologist, a social worker, a physical and occupational therapist, and a psychologist. Satisfaction ratings were measured using a multidimensional questionnaire involving a rating scale (0-10) and a structured telephone interview.

Results: 59 of the 65 patients who participated in the programme $(91 \%)$ completed the questionnaire. Patients were most satisfied with the interpersonal approach and professional knowledge, and least satisfied with the waiting time for the final report and the practical application of the given advice. Mean satisfaction score was 7.3 (SD 1.0). Twenty eight of the occupational physicians involved were interviewed. They were satisfied with the programme overall; 21 (75\%) stated that their role in the vocational rehabilitation process could be defined more clearly, and they would appreciate more contact with the team members, preferably in the early phases.

Conclusions: Patients' and occupational physicians' satisfaction with a multidisciplinary vocational rehabilitation programme was good. Areas for improvement mainly concerned the speed of the process and the communication between team members and occupational physicians.
\end{abstract}

$\mathrm{T}$ he impact of work disability in patients with rheumatic diseases is generally acknowledged and increasing attention is being paid to how return to work can be promoted. ${ }^{1-6}$ To optimise vocational guidance, specific vocational rehabilitation programmes have been introduced. In the health care setting, such programmes are usually run on an outpatient basis and are integrated with rehabilitation clinics or hospitals. ${ }^{7-9}$ The organisation and availability of such facilities vary greatly between countries. ${ }^{10}{ }^{11}$

In the Dutch health care system occupational physicians play an important role in the process of vocational rehabilitation. Occupational physicians are linked to occupational health services, with which all companies have been legally obliged to have a contract since January 1998. The cooperation between occupational physicians and other health professionals is an important but often troublesome element in the vocational guidance of patients with a health related problem at work. ${ }^{12-16}$ Apart from treatment and advice, enhancement of communications between patients, occupational physicians, and the other health care professionals is now part of any vocational rehabilitation programme. Up to now, there have been few attempts to evaluate interventions aimed at reducing work disability, ${ }^{17}$ and these have only included estimations of the number of patients maintaining or returning to a paid job as a single outcome measure. From the perspective of quality management, however, patients' and health professionals' satisfaction with complex health care processes is increasingly recognised as important. ${ }^{18} 19$

To improve the content and organisation of vocational rehabilitation programmes in a health care setting, we not only need data on clinical effectiveness but we also need to know what aspects of these programmes are seen to be satisfactory or unsatisfactory by the patients and health care professionals.

Our aim in the present study was therefore to describe patients' and occupational physicians' satisfaction with a multidisciplinary vocational rehabilitation programme for patients with chronic rheumatic diseases. Satisfaction with the organisation and content of the programme was measured shortly after the intervention had been completed. Because measuring outcome is a long term process, data on clinical effectiveness were gathered over a much longer period (two years) and will be published at a later stage.

\section{METHODS}

The study was undertaken between March 1999 and June 2001. Patients participated in a multicentre randomised controlled trial in which the cost-effectiveness of a multidisciplinary vocational rehabilitation programme was compared with the normal outpatient care initiated by the treating rheumatologist.

The satisfaction study involved only those patients attending the multidisciplinary job retention vocational rehabilitation programme at the department of rheumatology, Leiden University Medical Centre, during this period. The programme had been functioning for a year before the trial started. At the time the study was conducted, the programme was only available for patients participating in the trial, as its capacity was limited.

The satisfaction study comprised the completion by the patients of a single questionnaire concerning various aspects of the programme, and a structured telephone interview with the occupational physicians involved in their vocational guidance. 
The medical ethics committees of the hospitals involved approved the randomised clinical trial (including the satisfaction study).

\section{Patients}

Patients were eligible for enrolment in the randomised clinical trial if they had a chronic rheumatic disease with arthritis of one or more joints (rheumatoid arthritis or systemic lupus erythematosus (SLE), according to the American Rheumatism Association (ARA) classification criteria, ${ }^{20} 21$ ankylosing spondylitis according to the modified New York classification criteria, ${ }^{22}$ or reactive arthritis, psoriatic arthritis, or scleroderma). All patients perceived challenges in maintaining their jobs and were highly motivated to remain in or return to the workforce. Patients were either still working or had only recently been on sick leave (for less than one year). Allocation to either the vocational rehabilitation programme or the usual type of care was determined by randomisation. Patients were referred for screening for eligibility for the trial by their treating rheumatologist.

\section{The multidisciplinary vocational rehabilitation programme}

A multidisciplinary team-involving a rheumatologist, a social worker, a physical therapist, an occupational therapist, and a psychologist-ran the vocational rehabilitation programme. An occupational physician who was linked to the occupational health service of the Leiden University Medical Centre was also connected to the team. This occupational physician was not involved in the guidance of individual patients but had a general advisory role, being present only at the multidisciplinary team conferences. The organisation of the programme was in the hands of a coordinator (a social worker, JB, or a physical therapist, FvdG). All patients made at least two visits to the programme.

After enrolment, a standardised letter confirming the patient's participation and an information leaflet about the programme were sent by mail to the occupational physician involved in the guidance of the patient. All occupational physicians were invited to contact the coordinator of the team to exchange information or to join multidisciplinary team conferences about their patient. Depending on the company for which the patients worked, these occupational physicians were linked to various different occupational health services. However, according to Dutch law, the occupational physicians were only informed about their patient's participation in the programme if the patient had given written informed consent. ${ }^{23}$

The rheumatologist and the coordinator first carried out a systematic assessment. The assessment by the rheumatologist consisted of a history and physical examination, and included an evaluation of disease activity and joint destruction, and the presence of extra-articular manifestations or comorbidity. The assessment by the coordinator comprised a structured interview concerning the patient's education and previous jobs, and a systematic record of the problems encountered in the current work environment, using a list of potential challenges. The patient's psychosocial situation was also recorded.

Within two weeks after the initial assessment, a multidisciplinary team conference was held, at which all members of the team and the advisory occupational physician were present. During the conference, the patients' health problems, the challenges in remaining at work, and the development of individualised solutions were discussed..$^{24}$ If necessary, additional team members were asked to see the patient in order to gather more information about specific aspects of the work situation. Depending on the specific problems of the individual patient, the intervention further consisted of counselling, guidance, or treatment (for example, the identification of resources for adapting the work environment or the working hours, promotion of work self efficacy, referrals to other health professionals or adaptation of the medical treatment in consultation with the treating (referring) rheumatologist, exercise therapy, occupational therapy, functional training of relevant activities, or psychological treatment).

All information about the current disease characteristics and prognosis, the work situation, description of work problems, and the counselling or treatment options given by team members were listed in a final report, which was discussed with the patient by the team coordinator.

The final report was then sent to the rheumatologist who referred the patient, but was only sent to the occupational physician if the patient had given written informed consent. The total number of visits in connection with the vocational rehabilitation programme was at least two (assessments by rheumatologist and coordinator and discussion of the final report with the coordinator). The total duration of the intervention varied depending on the content of the individual guidance and treatment process, and lasted on average between four and 12 weeks.

\section{Assessments \\ Patients' sociodemographic variables and clinical data}

The following data were recorded before the patient entered the programme: age, sex, diagnosis, disease duration, and education level (divided into three categories based on the Dutch school system, primary education $0-8$ years, secondary education 9-16 years, and higher vocational education/ university 17+years). Work history and current working situation were recorded using parts of a Dutch generic structured instrument - the vocational handicap questionnaire (VHQ) - which has previously been validated in chronically ill Dutch people. ${ }^{26-28}$ Current occupation was grouped into four categories, each representing different levels and types of objective physical and mental demands at work. ${ }^{29}$ For the description of problems encountered in the current work situation, the team coordinator's records were used. Finally, the patients' overall satisfaction with their current job was scored on a visual analogue scale (VAS, range 0-10; anchor on the left: not at all satisfied; anchor on the right: fully satisfied). The VAS was only filled in by those patients who had worked for at least a few days in the last month.

\section{Patient satisfaction}

The patient satisfaction questionnaire comprised 22 questions and was based on two multidimensional questionnaires. One questionnaire was designed to describe satisfaction with occupational rehabilitation in employees with low back problems, ${ }^{30}$ and the other was developed and validated to measure satisfaction with multidisciplinary care in patients with rheumatoid arthritis. ${ }^{31}$ The final questionnaire comprised those domains of health care that have previously been found to be the most important according to the perception of quality of care by patients with rheumatoid arthritis. $^{32}$ The seven different domains in the final questionnaire comprised 22 statements on the following: the usefulness of the given advice $(n=2)$, the interpersonal approach $(\mathrm{n}=3)$, communication $(\mathrm{n}=2)$, professional knowledge $(n=5)$, effectiveness $(n=2)$, quality of information $(\mathrm{n}=3)$, coordination of care among team members $(n=2)$, and the quality of the final report $(n=3)$. The domains communication, interpersonal approach, professional knowledge, and usefulness of the advice given were 
derived from the back pain questionnaire. The domains effectiveness, quality of information, and coordination of care among team members were derived from the multidisciplinary care questionnaire. The questions on the quality of the final report were designed specifically for the present study. With each statement the patient was asked to agree or disagree using a five point Likert scale ( 1 , totally agree to 5 , totally disagree). Patients had the opportunity to give a written comment on each assertion in the questionnaire. In addition overall satisfaction with the vocational rehabilitation programme was measured on a rating scale $(0-10$ points: 0 , not satisfied; 10 , very satisfied). Patients were also asked if they would recommend the job retention vocational rehabilitation programme to others (yes or no).

Patients received the satisfaction questionnaire four to six weeks after termination of the programme. To prevent response bias, the questionnaire was filled in anonymously and sent back by mail to the principal investigator (PdB), who was not personally involved in the vocational rehabilitation programme.

\section{Occupational physicians satisfaction}

Six to 12 weeks after a patient had ended the vocational rehabilitation programme, the occupational physician from the occupational health service that was linked to the patient's company was contacted by telephone for a structured interview by the principal investigator (PdB). This was done only if the patient had given written informed consent for the exchange of information. The interview comprised 28 questions on the following: the occupational physicians' sociodemographic data (sex; in training or not), overall satisfaction with the written information concerning the vocational rehabilitation programme $(n=7)$, whether they had received and read the final report $(n=2)$, familiarity with the patient's problems at work $(n=1)$, satisfaction with the specific information provided concerning diagnosis, prognosis, work situation, and psychosocial situation, and satisfaction with the advice/suggestions given by the team to address these problems $(n=15)$.

The occupational physicians were also asked if they would have wanted to join the team meetings $(n=1)$. Their general opinion about the initiative of a hospital based team actively passing on information about the work situation to the occupational physician was sought $(\mathrm{n}=1)$, and they were asked about any suggestions for optimising the programme $(n=2)$. The average duration of the interview was 20 minutes.

\section{Analysis and statistical methods}

Data management was undertaken using the Project Manager software package, version 6.1 based on the Knowledge Man relational database system. ${ }^{33}$ Data were automatically and integrally converted to SPSS 10 for Windows for statistical analysis. Measures with a gaussian distribution are expressed as mean (SD); otherwise, medians and ranges are presented.

\section{RESULTS}

\section{Patients}

In all, 140 patients were enrolled in the randomised controlled trial. Using stratified randomisation by rheumatic disease and hospital, 75 were assigned to the vocational rehabilitation programme. Sixty five of these paid at least one visit to the hospital in connection with the programme and were included in the satisfaction study. In table 1, characteristics of the 65 participants in the programme are presented. Their median age was 45 years (range 21 to 57), and 37 (57\%) were female. The median disease duration was 16 months (range 0 to 158) and half the patients had rheumatoid
Table 1 Characteristics of patients with chronic rheumatic diseases $(n=65)$ participating in the multidisciplinary vocational rehabilitation programme

Sociodemographic characteristics

Age (years) (median (range))

45 (21 to 57$)$

Disease duration (months) (median (range)) $16(0$ to 158

Female patients

$37(57 \%)$

Diagnosis

Rheumatoid arthritis

Ankylosing spondylitis or other

spondylarthropathies

"Other"

$30(46 \%)$

Educational level

Low

Medium

$15(23 \%)$

High

$19(29 \%)$

$31(48 \%)$

$15(23 \%)$

Occupational category

Mental demands

Mixed mental/physical demands $\quad 13(20 \%)$

Light physical demands

$18(28 \%)$

Heavy physical demands

$16(24 \%)$

Vocational status

Sick leave

Duration of sick leave (weeks) (median

(range))

Maintaining employment

$34(52 \%)$

Work satisfaction (0-10)

VAS work satisfaction $(n=51)$ (mean (SD)) 5.4 (2.5)

Values are $\mathrm{n}(\%)$ unless stated.

*Other: chronic rheumatic diseases such as systemic lupus erythematosus, chronic gout, mixed connective tissue disease.

arthritis. Fifty (77\%) of the patients had secondary education or less, which appeared to be a representative sample given the distribution in a nationwide sample of Dutch patients with rheumatoid arthritis ${ }^{34}$ and the Dutch population. ${ }^{35}$ Thirty one of the patients (48\%) reported mentally demanding or mixed mentally and physically demanding work, 18 $(28 \%)$ reported light physical demands, and 16 (24\%) reported heavy physical demands at work. Thirty four patients $(52 \%)$ were on sick leave because of their rheumatic disease. In these patients the mean duration of sick leave was 16 weeks (range 1 to 52). Mean (SD) level of job satisfaction before participation in the vocational rehabilitation programme, as measured with a VAS, was $5.4(2.5)(\mathrm{n}=51)$.

\section{The vocational rehabilitation programme}

The median number of visits in connection with the vocational rehabilitation programme was three (range one to six). The median number of health professionals involved was five (range two to six). After the initial assessment by the rheumatologist and the coordinator, the social worker was involved with 41 patients (63\%), the occupational therapist with $50(77 \%)$, the physical therapist with 48 (74\%), and the psychologist with four $(6 \%)$.

The self reported challenges in remaining at work are presented in table 2. The mean (SD) number of problems reported per patient was 5 (3). Pain and fatigue were the most cited disease related challenges. Overall, more than 30\% of the patients reported challenges associated with specific labour conditions such as using grip force, carrying loads, standing, and exposure to climatic conditions such as cold, heat, and damp.

\section{Patient satisfaction}

Fifty nine $(91 \%)$ of the 65 patients returned the satisfaction questionnaire. The results show that the aspects of care most 
Table 2 Number of self reported challenges in remaining at work in 65 patients with chronic rheumatic diseases participating in the vocational rehabilitation programme

\begin{tabular}{|c|c|}
\hline Complaint & $\begin{array}{l}\text { Patients reporting this } \\
\text { problem (n (\%)) }\end{array}$ \\
\hline $\begin{array}{l}\text { Tiredness during work } \\
\text { Tiredness after work } \\
\text { Tiredness, general } \\
\text { Pain } \\
\text { Morning stiffness } \\
\text { Swollen joints }\end{array}$ & $\begin{array}{l}6(10 \%) \\
8(12 \%) \\
15(23 \%) \\
23(35 \%) \\
10(15 \%) \\
0(0 \%)\end{array}$ \\
\hline $\begin{array}{l}\text { Labour conditions in general } \\
\text { Time pressure } \\
\text { Working hours, starting early in the morning } \\
\text { Rigid schedule } \\
\text { Shift work }\end{array}$ & $\begin{array}{l}9(14 \%) \\
10(15 \%) \\
2(3 \%) \\
2(3 \%)\end{array}$ \\
\hline $\begin{array}{l}\text { Specific labour conditions: lower extremities } \\
\text { Sitting } \\
\text { Standing } \\
\text { Kneeling } \\
\text { Bending } \\
\text { Walking } \\
\text { Climbing stairs } \\
\text { Repetitive movements legs }\end{array}$ & $\begin{array}{l}17(26 \%) \\
22(34 \%) \\
13(20 \%) \\
12(19 \%) \\
15(23 \%) \\
7(11 \%) \\
1(2 \%)\end{array}$ \\
\hline $\begin{array}{l}\text { Specific labour activities: upper extremities } \\
\text { Repetitive movements arms } \\
\text { Reaching } \\
\text { Carrying } \\
\text { Overhead work } \\
\text { Manual precision work or writing } \\
\text { Using grip force }\end{array}$ & $\begin{array}{l}13(20 \%) \\
0(0 \%) \\
21(32 \%) \\
10(15 \%) \\
17(26 \%) \\
29(45 \%)\end{array}$ \\
\hline $\begin{array}{l}\text { Transportation to and from work } \\
\text { Walking } \\
\text { Cycling } \\
\text { Car or motor } \\
\text { Public transport } \\
\text { Parking }\end{array}$ & $\begin{array}{l}0(0 \%) \\
2(3 \%) \\
9(14 \%) \\
3(5 \%) \\
3(5 \%)\end{array}$ \\
\hline $\begin{array}{l}\text { Accessibility in workplace } \\
\text { Stairs } \\
\text { Doors } \\
\text { Toilet }\end{array}$ & $\begin{array}{l}1(2 \%) \\
1(2 \%) \\
1(2 \%)\end{array}$ \\
\hline Exposure to cold, heat, or damp & $20(31 \%)$ \\
\hline $\begin{array}{l}\text { Workplace inventory } \\
\text { Desk } \\
\text { Chair } \\
\text { Computer/mouse } \\
\text { Tools }\end{array}$ & $\begin{array}{l}8(12 \%) \\
11(16 \%) \\
1(2 \%) \\
8(12 \%)\end{array}$ \\
\hline $\begin{array}{l}\text { Psychosocial } \\
\text { Relations with supervisor or colleagues }\end{array}$ & $13(20 \%)$ \\
\hline $\begin{array}{l}\text { Situation at home } \\
\text { Acceptance of disease by patient } \\
\text { Acceptance of disease by family or friends } \\
\text { Social activities with children, family, or } \\
\text { friends }\end{array}$ & $\begin{array}{l}2(3 \%) \\
3(5 \%) \\
4(6 \%)\end{array}$ \\
\hline
\end{tabular}

highly rated were the interpersonal approach and the professional knowledge of the health professionals involved in the programme (table 3). Patients were least satisfied with the waiting time for the final report and the application of the advice given in the actual work situation. The mean satisfaction score was 7.3 (1.0). Eighty five patients (98\%) said they would recommend the programme to other patients. Most additional written comments were confirmations of the answers on the Likert scales. None of the comments were about a lack of understanding of a question. These findings substantiate the feasibility of the questionnaire.
Table 3 Patient satisfaction* with a vocational rehabilitation team ( $n=59$ patients)

\begin{tabular}{|c|c|}
\hline Question & Median (range) \\
\hline \multicolumn{2}{|l|}{ Usefulness } \\
\hline Contact with the team in general was good & $2(1$ to 3$)$ \\
\hline Contact with the team has been very useful & $2(1$ to 4$)$ \\
\hline \multicolumn{2}{|l|}{ Interpersonal approach } \\
\hline Health professionals had respect for me & $2(1$ to 4$)$ \\
\hline Health professionals were interested in me & $2(1$ to 3$)$ \\
\hline Health professionals were very friendly & $2(1$ to 4$)$ \\
\hline \multicolumn{2}{|l|}{ Communication } \\
\hline $\begin{array}{l}\text { A lot of verbal information was provided about } \\
\text { possibilities of remaining in the workforce }\end{array}$ & $2(1$ to 5$)$ \\
\hline $\begin{array}{l}\text { Health professionals listened to my wishes } \\
\text { and ideas concerning care }\end{array}$ & $2(1$ to 3$)$ \\
\hline \multicolumn{2}{|l|}{ Professional knowledge } \\
\hline $\begin{array}{l}\text { Health professionals had experience with my } \\
\text { problems }\end{array}$ & $2(1$ to 4$)$ \\
\hline Health professionals gave good explanations and & 2 (1 to 4 ) \\
\hline Health professionals had good technical skills & $2(1$ to 4$)$ \\
\hline Health professionals knew what they were talking & \\
\hline about & 2 (1 to 4$)$ \\
\hline Health professionals gave impossible advice & $2(1$ to 5$)$ \\
\hline \multicolumn{2}{|l|}{ Effectiveness } \\
\hline $\begin{array}{l}\text { The programme had a positive effect on my work } \\
\text { situation }\end{array}$ & $3(1$ to 5$)$ \\
\hline The advice given was very useful & $2(1$ to 4$)$ \\
\hline \multicolumn{2}{|l|}{ Quality of information: general } \\
\hline $\begin{array}{l}\text { Written information about goals and methods was } \\
\text { good }\end{array}$ & $2(1$ to 5$)$ \\
\hline \multicolumn{2}{|l|}{ Quality of information: individual } \\
\hline Advice given was clear and practical & $2(1$ to 5$)$ \\
\hline The first meeting was very informative & $2(1$ to 5$)$ \\
\hline \multicolumn{2}{|l|}{ Coordination } \\
\hline \multicolumn{2}{|l|}{ The team members knew from each other what they } \\
\hline Collaboration among the care providers was good & $3(1$ to 5$)$ \\
\hline \multicolumn{2}{|l|}{ Final report } \\
\hline The results of the programme were well summarised & $2(1$ to 5$)$ \\
\hline The final visit was very useful & $2(1$ to 5$)$ \\
\hline $\begin{array}{l}\text { The final report was written promptly after the } \\
\text { guidance had ended }\end{array}$ & $3(1$ to 5$)$ \\
\hline
\end{tabular}

\section{Occupational physician satisfaction}

Fifty three patients (82\%) gave permission to contact their occupational physician. We were able to interview 28 (53\%) of these. Twenty five (47\%) could not be interviewed for the following reasons: six had changed jobs, eight stated they did not know the patient well enough to answer the questions, six did not respond to our repeated telephone calls, one required reimbursement for participating in the interview, two found that the patients' files were missing, and a further two could not be reached at all. Fifty per cent $(n=14)$ of the occupational physicians had been trained as such and had been working as occupational physicians for a median period of 6.2 years (range 1 to 22 ). Ten were in training to become occupational physicians, and four were general practitioners working as occupational physicians. These latter were not in training.

Occupational physicians' satisfaction ratings are is presented in table 4 . Overall satisfaction with the information provided was good. Almost all the occupational physicians stated that they thought it was a good initiative to pass on information from a hospital based vocational rehabilitation programme to the occupational health services. However, 
Table 4 Occupational physicians' (OPs) satisfaction with the vocational rehabilitation programme $(n=28)$

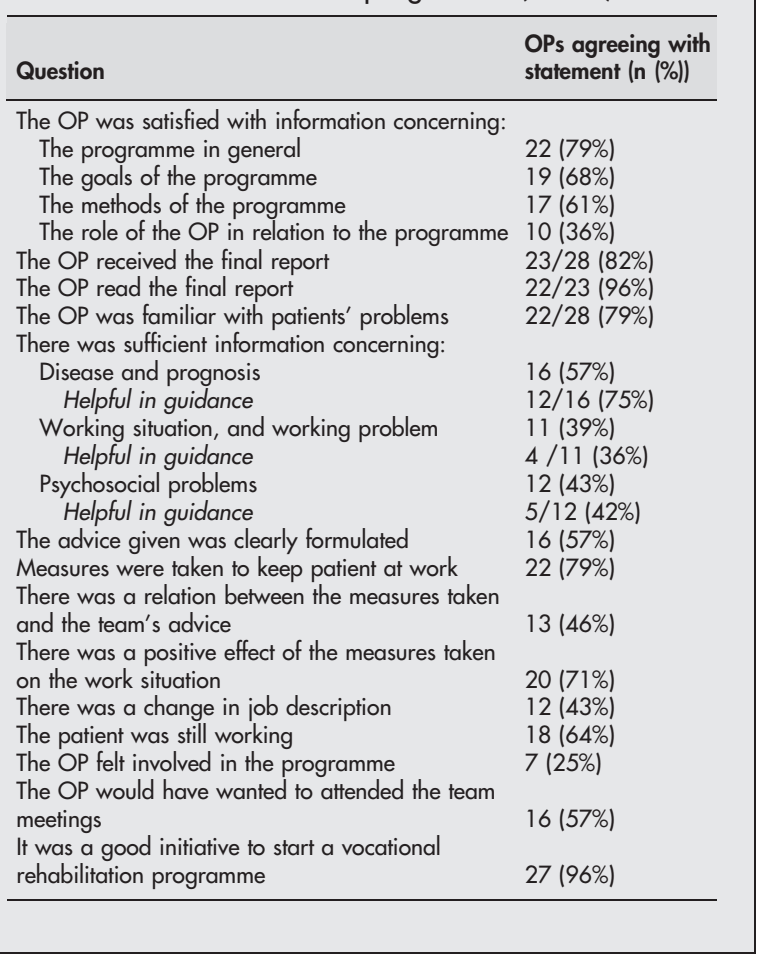

they found that the role of the occupational physician as a potential participant in the vocational rehabilitation programme should be explained more clearly in the information leaflet and letter provided at the start of the intervention. They also thought that communication should take place at an even earlier stage of the guidance process in cases of work problems.

All but one of the occupational physicians were familiar with the patient's problems at work. Most $(n=23 ; 82 \%)$ had received the final report. The number of occupational physicians agreeing with the statement that the final report contained sufficient information about the disease and prognosis was 16 (57\%); about the work situation and the challenges in maintaining work, 11 (39\%); and about the psychosocial situation of the patient, $12(43 \%)$.

According to $21(75 \%)$ of the occupational physicians, the information on the disease characteristics and prognosis was helpful. Information about the work and psychosocial situation was found to be sufficient by 16 (57\%), but only a small number thought that it was of additional value in providing guidance. Several of the occupational physicians felt that if the team members could have visited the workplace, the practical application of the advice given might have improved.

\section{DISCUSSION}

Our study uncovered several areas of satisfaction or dissatisfaction with a job retention vocational rehabilitation programme for patients with chronic rheumatic diseases. This information may be helpful in improving the content and organisation of similar programmes that are executed in the complex context of vocational guidance. Overall, satisfaction with the programme was good. Points that needed attention as indicated by the patients were the waiting time for the final report, and the application of the given advice or potential solutions in the actual work situation. The occupational physicians felt that their role as potential participants in the vocational rehabilitation process should be explained more clearly, and there should be more communication at earlier phases of the vocational guidance.

This study is the first to examine satisfaction ratings by patients as well as by their occupational physicians in relation to a multidisciplinary job retention vocational rehabilitation programme in a health care setting.

A limitation of the study was the lack of any measurement of the patients' expectations before the intervention, so we cannot relate the satisfaction scores to individual levels or needs. ${ }^{36}$ Moreover, selection bias may play a role in the interpretation of the levels of satisfaction. The patients described in this study were a highly motivated group who had high hopes of remaining at work or returning to the workforce. It is not clear whether this selection bias influences satisfaction levels positively or negatively, but nevertheless the results cannot be generalised to the total population of rheumatic patients taking part in job retention programmes.

Selection bias might also have played a role in the occupational physicians' satisfaction results, as we were able to interview only $53 \%$ of the physicians involved. This relatively low response rate did, however, appear to be related mainly to the organisation of occupational health care services rather than to the quality of the vocational rehabilitation programme.

The patient satisfaction results obtained in our study are in general slightly less positive than those obtained in a recent study by Allaire et al. In that study, the investigators measured the patients' satisfaction with and the perceived helpfulness of a vocational rehabilitation programme run in a community setting in the USA. ${ }^{37}$ In all, 242 employed patients with rheumatoid arthritis, osteoarthritis, or SLE, who perceived they were at risk for work disability, were enrolled in the trial. Using stratified randomisation by age, type of rheumatic disease, and location, 122 subjects were assigned to the experimental group. They received job retention vocational rehabilitation services-for example, assessment of work related problems and development of solutions-during two meetings with a rehabilitation counsellor, each lasting 1.5 hours. Satisfaction and perceived helpfulness were measured using $1-10$ scales ( $10=$ very helpful or satisfied). Median satisfaction score was 10 (interquartile range, 1.0) and median helpfulness was scored 9 (interquartile range, 2.0).

As the setting of the interventions and the process of vocational guidance vary greatly between the USA and the Netherlands (mostly because of differences in the occupational health care and social security systems), a direct comparison of the results of the study by Allaire and the present study is difficult.

In our study, we also measured satisfaction on the part of the occupational physicians-who in the Dutch situation may be considered as an additional group of clients of the programme. Almost all occupational physicians stated it was a good initiative to pass on information from within a hospital based vocational rehabilitation programme to the occupational health services. However, according to the occupational physicians their role as potential participants in the vocational rehabilitation process should be explained more clearly. In our study, the occupational physicians were not a part of the vocational rehabilitation team but were asked to collaborate with the team by keeping in contact by mail or phone. However, most of them did not feel sufficiently involved in the process, or appeared not to be aware of the working methods of the programme. Our study substantiates the results of earlier ones in which it was shown that there is a need for better job descriptions and improved cooperation between health professionals working 
in vocational rehabilitation. ${ }^{38}{ }^{39}$ Within the field of rheumatology, a perceived lack of clarity about mutual tasks has been presented before as a major obstacle in communication between Dutch rheumatologists and occupational physicians. $^{40}$ This highlights a limitation of the intervention employed in the present study. Because the setting of the intervention was hospital based, communication was confined to areas where occupational physicians might have been able to provide additional information. The intervention as described in the present study was therefore predominantly concerned with the one sided perspective of the patient-perceived challenges of remaining at work. Extended cooperation with occupational physicians might improve the analysis of the work problems and the practical application of advice and solutions provided by the team members. However, our results indicate that contacting occupational physicians can be difficult or may be considered undesirable by the patient in some cases. The fact that many occupational physicians wished to play a more active role is nevertheless a positive starting point for improving the vocational guidance process.

In contrast to most published reports on vocational rehabilitation programmes, which have focused on patients with permanent work disability or job loss, the focus of our programme was on patients who were still employed and on the identification of challenges in their current workplace. Only a few previous studies have addressed these issues and our results are in general agreement with their findings. ${ }^{41-44}$ Disease related challenges that were most often cited in our study were pain and fatigue, while more than $30 \%$ of the patients reported challenges that were associated with specific labour conditions such as the use of hand grip, load carrying, standing, and exposure to climatological circumstances like cold, heat, and damp.

Now that we are aware of the challenges faced by patients with chronic rheumatic diseases in their workplace, and the perceived bottlenecks in the process of vocational rehabilitation, the results of this study will help us to improve our own and similar vocational rehabilitation programmes for patients with rheumatic diseases. To determine the exact place of such programmes in the management of such patients we need greater knowledge about their efficacy in different settings. Apart from the results of some uncontrolled studies, ${ }^{17}$ the preliminary results of a randomised controlled trial ${ }^{45}$ describing the efficacy of a job retention vocational rehabilitation service show promise for the future. The results of the present randomised clinical trial are about to be published.

\section{ACKNOWLEDGEMENTS}

We would like to thank Jacqueline Boon for gathering patient data; Bart Muis, medical student; for gathering occupational physician data; all health professionals participating in the job retention vocational rehabilitation programme; and the participating rheumatologists for referring patients: A J Peeters and D van Zeben, Reinier de Graaff Hospital, Delft; M L Westedt and I Speijer, Bronovo Hospital, The Hague; H K Ronday, Hospital Leyenburg, The Hague; J A P M Ewals, Rode Kruis Hospital, The Hague; G Collée and W M de Beus, Medical Centre Haaglanden, The Hague; J P Terwiel, A Linssen, C Mallee, Spaarne and Kennemer Hospitals, Haarlem; and J M Bok, Groene Hart Hospital, Gouda.

\section{Authors' affiliations \\ P D M de Buck, Department of Rheumatology and Medical Decision Making, Leiden University Medical Centre, Leiden, Netherlands J Breedveld, Department of Social Work, Leiden University Medical Centre \\ F J van der Giesen, Department of Physical and Occupational Therapy, Leiden University Medical Centre \\ T P M Vliet Vlieland, Department of Rheumatology, Leiden University Medical Centre}

\section{REFERENCES}

1 Guillemin F, Briancon S, Pourel J, Gaucher A. Long-term disability and prolonged sick leaves as outcome measurements in ankylosing spondylitis. Possible predictive factors. Arthritis Rheum 1990;33:1001-6.

2 Allaire SH, Partridge AJ, Andrews HF, Liang MH. Management of work disability. Resources for vocational rehabilitation. Arthritis Rheum 1993;36: 1663-70.

3 Partridge AJ, Karlson EW, Daltroy LH, Lew RA, Wright EA, Fossel AH, et al. Risk factors for early work disability in systemic lupus erythematosus: results from a multicenter study. Arthritis Rheum 1997;40:2199-206.

4 Chorus AM, Miedema HS, Wevers CW, van Der LS. Work factors and behavioural coping in relation to withdrawal from the labour force in patients with rheumatoid arthritis. Ann Rheum Dis 2001;60:1025-32.

5 Mau W, Bornmann M, Weber H, Weidemann HF, Hecker $\mathrm{H}$, Raspe HH. Prediction of permanent work disability in a follow-up study of early rheumatoid arthritis: results of a tree structured analysis using RECPAM. Br J Rheumatol 1996;35:652-9.

6 Broersen JP, de Zwart BC, van Dijk FJ, Meijman TF, van Veldhoven M. Health complaints and working conditions experienced in relation to work and age. Occup Environ Med 1996;53:51-7.

7 Schmidt SH, Oort-Marburger D, Meijman TF. Employment after rehabilitation for musculoskeletal impairments: the impact of vocational rehabilitation and working on a trial basis. Arch Phys Med Rehabil 1995;76:950-4

8 Karjalainen K, Malmivaara A, van Tulder M, Roine R, Jauhiainen M, Hurri H, et al. Multidisciplinary rehabilitation for fibromyalgia and musculoskeletal pain in working age adults. Cochrane Database Syst Rev 2000;2:CD001984.

9 Andersson B, Hagerstrom M, Nordh-Grate K, Nordmark B, Ronnqvist R. Can early multidisciplinary team care preserve work capacity for patients with rheumatoid arthritis? Ann Rheum Dis 1999;58:S107

10 Lehnert G, Wrbitzky R. Occupational health in Germany and other countries of the European Union. Int J Occup Med Environ Health 1998;11:9-18.

11 Franco G. Occupational physicians' education and training across European Union countries. Int Arch Occup Environ Health 1999;72:338-42.

12 van Amstel R, Buijs P. Voor verbetering vatbaar (deel 1). Dutch general practitioners and their co-operation with occupational physicians in vocational rehabilitation. TNO work and employment. The Netherlands: Hoofddorp, 1997.

13 van Amstel R, Buijs P. Voor verbetering vatbaar (deel 2). Dutch medical specialists and their co-operation with occupational physicians in vocational rehabilitation. TNO work and employment. The Netherlands: Hoofddorp, 2001, Reportnumber 1070110.

14 van Dijk FJ, Prins R. Occupational health care and work incapacity: recent developments in The Netherlands. Occup Med (Lond) 1995;45:159-66.

15 Mau W, Bornmann M, Weber H, Weidemann HF. Deficiencies in rehabilitation measures in the course of early chronic polyarthritis. Z Rheumatol 1996;55:223-9.

16 Gilworth G, Haigh R, Tennant A, Chamberlain MA, Harvey AR. Do rheumatologists recognize their patients' work-related problems? Rheumatology (Oxf) 2001;40:1206-10.

17 de Buck PD, Schoones JW, Allaire SH, Vliet Vlieland TP. Vocational rehabilitation in patients with chronic rheumatic diseases: a systematic literature review. Semin Arthritis Rheum 2002;32:196-203.

18 Weiss BD, Senf JH. Patient satisfaction survey instrument for use in health maintenance organizations. Med Care 1990;28:434-45.

19 McMillan JR. Measuring consumer satisfaction to improve quality of care. Health Prog 1987;68:54-80.

20 Arnett FC, Edworthy SM, Bloch DA, McShane DJ, Fries JF, Cooper NS, et al. The American Rheumatism Association 1987 revised criteria for the classification of rheumatoid arthritis. Arthritis Rheum 1988;31:315-24.

21 Tan EM, Cohen AS, Fries JF, Masi AT, McShane DJ, Rothfield NF, et al. The 1982 revised criteria for the classification of systemic lupus erythematosus. Arthritis Rheum 1982;25:1271-7.

22 van Der Linden S, Valkenburg HA, Cats A. Evaluation of diagnostic criteria for ankylosing spondylitis. A proposal for modification of the New York criteria. Arthritis Rheum 1984;27:361-8.

23 Royal Dutch Medical Association Manual. Utrecht, the Netherlands: KNMG, 1992.

24 Merkesdal S, Ruof J, Schoffski O, Bernitt K, Zeidler H, Mau W. Indirect medical costs in early rheumatoid arthritis: composition of and changes in indirect costs within the first three years of disease. Arthritis Rheum 2001;44:528-34.

25 Mancuso CA, Paget SA, Charlson ME. Adaptations made by rheumatoid arthritis patients to continue working: A pilot study of work place challenges and successful adaptations. Arthritis Care Res 2000;13:89-99.

26 Andries F, Wevers CW, Wintzen AR, Busch HF, Howeler CJ, de Jager AE, et al. Vocational perspectives and neuromuscular disorders. Int J Rehabil Res 1997;20:255-73.

27 Wevers CW, Brouwer OF, Padberg GW, Nijboer ID. Job perspectives in facioscapulohumeral muscular dystrophy. Disabil Rehabil 1993;15:24-8

28 Niiboer ID, Wevers CJ. Vocational rehabilitation of young adults with a disability of one arm or hand. Int J Rehabil Res 1993;16:45-7.

29 de Zwart BC, Broersen JP, van der Beek AJ, Frings-Dresen MH, van Dijk FJ. Occupational classification according to work demands: an evaluation study. Int J Occup Med Environ Health 1997; 10:283-95.

30 van der Weide WE, Verbeek JH, van Dijk FJ. Relation between indicators for quality of occupational rehabilitation of employees with low back pain. Occup Environ Med 1999;56:488-93.

31 Tijhuis GJ, Kooiman CG, Zwinderman AH, Hazes JMW, Breedveld FC, Vliet Vlieland TPM. Validation of a novel satisfaction questionnaire for patients with 
rheumatoid arthritis receiving outpatient clinical nurse specialist care, inpatient or day patient team care. Arthritis Rheum 2003;49:193-9.

32 van der Waal MA, Casparie AF, Lako CJ. Quality of care: a comparison of preferences between medical specialists and patients with chronic diseases. Soc Sci Med 1996:42:643-9.

33 Brand R. Project Manager soffware by Medical Research Data Management. The Netherlands: Leiden University Medical Centre, 1997.

34 Boonen A, Chorus A, Miedema H, van der HD, Landewe R, Schouten $\mathrm{H}$, et al. Withdrawal from labour force due to work disability in patients with ankylosing spondylitis. Ann Rheum Dis 2001;60:1033-9.

35 Central bureau of statistics. Statistisch Jaarboek 2000. Heerlen/ Voorburg: sdu, Den Haag, 2000

36 van Campen C, Sixma HJ, Kerssens JJ, Peters L, Rasker JJ. Assessing patients' priorities and perceptions of the quality of health care: the development of the QUOTE-Rheumatic-Patients instrument. Br J Rheumatol 1998;37:362-8.

37 Allaire SH, Li W, La Valley MP. Are persons with rheumatic diseases willing to pay for job retention vocational rehabilitation (VR) services? Arthritis Rheum 2002:46:S560.

38 Buijs $\mathbf{P}$, van Amstel R, van Dijk F. Dutch occupational physicians and general practitioners wish to improve cooperation. Occup Environ Med 1999;56:709-13.
39 de Bono AM. Communication between an occupational physician and other medical practitioners - an audit. Occup Med (Lond) 1997;47:349-56.

40 de Buck PD, van Amstel RJ, Buijs PC, Maasen JH, van Dijk FJ, Hazes JM, et al Communication between Dutch rheumatologists and occupational physicians in the occupational rehabilitation of patients with rheumatic diseases. Ann Rheum Dis 2002;61:62-5.

41 Mitchell JM, Burkhauser RV, Pincus T. The importance of age, education, and comorbidity in the substantial earnings losses of individuals with symmetric polyarthritis. Arthritis Rheum 1988;31:348-57.

42 Yelin E, Henke C, Epstein W. The work dynamics of the person with rheumatoid arthritis. Arthritis Rheum 1987;30:507-12.

43 Doeglas D, Suurmeijer T, Krol B, Sanderman R, van Leeuwen M, van Rijswijk M. Work disability in early rheumatoid arthritis. Ann Rheum Dis 1995;54:455-60

44 van Jaarsveld $\mathrm{CH}$, Jacobs JW, Schrijivers AJ, Albada-Kuipers GA, Hofman DM, Bijlsma JW. Effects of rheumatoid arthritis on employment and social participation during the first years of disease in The Netherlands. Br J Rheumatol 1998;37:848-53.

45 Allaire SH, Li W, La Valley MP. A randomized trial with 3.5 years follow-up shows job retention vocational rehabilitation services reduce job loss. Arthritis Rheum 2002;46:S580. 